\title{
Experimental weed control of Najas marina ssp. intermedia and Elodea nuttallii in lakes using biodegradable jute matting
}

\author{
Markus A. HOFFMANN, ${ }^{*}$ Alberto BENAVENT GONZÁLEZ, Uta RAEDER, Arnulf MELZER \\ Limnologische Station, Technische Universität München, Hofmark 1-3, 82393 Iffeldorf, Germany \\ *Corresponding author: Markus.Hoffmann@tum.de
}

\begin{abstract}
The use of jute matting in managing the invasive aquatic macrophyte species Elodea nuttallii (Planch.) H. St. John and Najas marina ssp. intermedia (Wolfg. ex Gorski) Casper (Najas intermedia) was studied in laboratory experiments and field trials. Four German lakes with predominant population of Najas intermedia or Elodea nuttalli were chosen for the experiment and areas between 150 and $300 \mathrm{~m}^{2}$ were covered with jute textile. The effect of the matting on the growth of invasive and non-invasive macrophytes was determined through comparison with control transects. Biodegradable jute matting successfully suppressed the invasive macrophyte Najas intermedia and significantly reduced the growth of Elodea nuttalli in lakes. The results indicate that the capability of the matting to inhibit the growth of Elodea nuttallii and Najas intermedia depends on the mesh size of the jute weaving and that environmental conditions can affect its efficiency. Various indigenous species like Charales or Potamogeton pusillus L. were able to grow through the jute fabric and populate the treated areas. Until the end of the vegetation period, none of the invasive species were able to penetrate the covering and establish a stable population; in fact, in the subsequent year the jute matting affected only the spread of Najas intermedia. Jute matting proved to be an easy-to-use and cheap method to control the growth of Elodea nuttallii and Najas intermedia.
\end{abstract}

Key words: benthic barrier, jute, weed control, invasive species.

Received: August 2012. Accepted: April 2013.

\section{INTRODUCTION}

Invasive native and non-native species like Najas marina ssp. intermedia (Wolfg. ex Gorski) Casper (Najas intermedia) and Elodea nuttallii (Planch.) H. St. John pose a growing problem for lakes in Germany. Their excessive growth has often a negative influence on the economic interests of fisheries and tourism (e.g. by restricting angling, boating, swimming and other water-based leisure activities), for example in the reservoirs along the river Ruhr (Podraza et al., 2008). The impact of invasive species on the biodiversity of lakes can be severe and is often caused by competition with the often less robust native species or by altering the native habitat in which they reside (Barrat-Segretain, 2005; Erhard and Gross, 2006; Erhard et al., 2007; Kelly and Hawes, 2005). Weed control in aquatic habitats can be difficult, especially in Germany, where the management is limited to mechanical control methods, because chemical and biological control methods, like the use of herbicides or grass carps, are often extremely restricted or prohibited. The method most commonly applied in German lakes is cutting and harvesting of macrophytes. This method, however, has various disadvantages; namely that it is often costly and, because it is non-specific concerning the affected plants, cutting and harvesting lacks sustainability (Pieterse and Murphy, 1990; Podraza et al., 2008). Usually, this leads to short- term effects only or, as in the case of Elodea nuttallii, can even cause the unintentional spread of fragments.

Another approach to aquatic weed control, which has been successfully applied in Ireland (Caffrey et al., 2010), is light exclusion through the use of benthic barriers, namely jute matting. Jute is a vegetable fiber produced from the plants Corchorus olitorius L. and Corchorus capsularis L. that can be spun into strong threads. Jute textiles are often used in the civil engineering applications and landscaping as geotextiles. Caffrey et al. (2010) were able to successfully inhibit the growth of the invasive macrophyte Lagarosiphon major (Ridley) moss in lough Corrib and to restore native macrophyte communities to areas of the lake that were previously overgrown by $L a$ garosiphon major. The method used by Caffrey et al. (2010) is based on experiences gained by the use of plastic foil in lake restoration (Hilt et al., 2006) and weed control (Boylen et al., 1996; Mayer, 1978; Pieterse and Murphy, 1990). The use of plastic material has considerable disadvantages as it is very difficult to sink and secure to the lake bed (Caffrey and Acevedo, 2007; Hilt et al., 2006; Mayer, 1978) and might release unwanted chemicals into the water (Yang et al., 2011). Additionally, the gas evolution that results from decaying plant matter beneath the cover and bacterial activity in the sediment can interfere with the long-term functioning and stability of the cover (Gunnison and Barko, 1992). Plastic matting can also af- 
fect the exchange of nutrients and gas between the water column and the benthos (Mayer, 1978), therefore harming native non-invasive macrophytes and macroinvertebrates (Ussery et al., 1997). Furthermore, the plastic material requires seasonal maintenance and ultimate removal from the habitat; the whole operation can produce significant costs and expenditure of time. On the other hand, jute has considerable advantages compared to plastic as it is a natural biodegradable material and easy to handle and to work with (Caffrey et al., 2010). Based on the results by Caffrey et al. (2010), a study was initialised to adapt the method to German lakes, respectively the two invasive macrophytes Elodea nuttallii and Najas intermedia. In contrast to Caffrey et al. (2010), jute mattings with different mesh sizes were tested for their ability to inhibit the growth of Elodea nuttalli during a preliminary experiment in climate chambers. The most successful matting was then tested under natural conditions in four different lakes.

Elodea nuttallii is a neophyte introduced to Germany in 1953 (Hussner et al., 2010; Weber-Oldecop, 1977) and is displacing the neophyte Elodea canadensis Michx. which had spread across German lakes since the $19^{\text {th }}$ century (Bolle, 1865). Today Elodea nuttalli can be found in almost all large lakes across Germany, but also in smaller lakes like the basins along the river Ruhr (Podraza et al., 2008). In Germany, only female plants are present, therefore Elodea nuttallii is only able to reproduce vegetatively. Najas intermedia, on the other hand, is a native species which has almost vanished from German lakes and is on the German Red List 2. About ten years ago Najas intermedia started to spread from its remaining habitats into other lakes. Direct enquiries at the water management offices (environmental agencies) revealed numerous dominant populations in lakes across Germany. Najas intermedia is especially successful in small, shallow lakes or ponds with summer temperatures above $20^{\circ} \mathrm{C}$ (M. Hoffmann, personal observation). The plants are dioecious and can only reproduce through seeds which can survive for up to three years in the sediment (Agami and Waisel, 1984; Handley and Davy, 2005). Mass occurrences of Najas intermedia have a negative effect on the ecological evaluation of lakes; indeed, transects dominated by Najas intermedia are counted as degraded (Schaumburg et al., 2007). Additionally, because of the numerous spikes located at the leaves and the internodes of Najas intermedia, mass occurrences can interfere with tourism, more precisely water-based leisure activities like swimming. Given the preference of both species for warm water temperatures and the predicted increase in water temperature (George 2010; IPCC, 2007), it can be assumed that the problems caused by Elodea nuttallii and Najas intermedia will increase and that new methods for managing mass occurrences of macrophytes will be needed.
The objectives of this study were to determine whether jute fabric is able to effectively control the invasive species Elodea nuttallii and Najas intermedia in lakes and to determine its effect on the growth of non-invasive macrophytes.

\section{METHODS}

\section{Preliminary test}

A laboratory experiment was conducted from October to December 2010 to determine the mesh size to successfully inhibit the growth of Elodea nuttallii. The experiment consisted of 12 aquariums measuring $60 \times 30 \times 25 \mathrm{~cm}$ (width $\times$ high $\times$ depth) each, filled with a 5-cm-layer of lake sediment collected from the lake Ringsee and tap water. Tap water was used to assure a constant water quality, if water had to be added to the aquariums to maintain a constant water level. Each aquarium was planted with 30 Elodea sprouts collected from lake Ringsee with an initial length of $5 \mathrm{~cm}$. The aquariums were stored in a climate chamber at a constant temperature of $20^{\circ} \mathrm{C}$, a light intensity of 215 $\mu \mathrm{mol}$ photons $\mathrm{m}^{-2} \mathrm{~s}^{-1}$ and a 12-hour day-night cycle. After two weeks of growth, the Elodea nuttallii plants were covered with jute textile. Three treatments of untreated jute textile were used in the experiment (Fig. 1), a light textile with $150 \mathrm{gm}^{-2}$ and a mesh size of $2 \mathrm{~mm}$, a medium textile with $200 \mathrm{gm}^{-2}$ and a mesh size of $1 \mathrm{~mm}$, and a heavy textile with $300 \mathrm{gm}^{-2}$ and a mesh size of $0.5 \mathrm{~mm}$. Every set-up was replicated three times; three aquariums were left uncovered to serve as control. The edges of the textiles were weighted with small stones to prevent Elodea from growing past the textile and to maintain a complete cover of the plants. After two months the covering textiles were removed and the Elodea nuttallii plants were examined. At the end of the experiment the $\mathrm{pH}$, the $\mathrm{O}_{2}$ concentration and the conductivity of the water above and (through a small incision) below the matting were measured for each aquarium (Tab. 1).

\section{Field trial}

Two Elodea nuttallii and two Najas intermedia dominated sites in four different lakes across southern Germany were selected for the field trials (Tab. 2). The experimental sites were selected based on macrophyte assessments carried out for the European Water Framework Directive between 2006 and 2009 by the Bavarian Environmental Agency (LfU) and on own assessments in 2010. All assessments were conducted by divers according to the Instructions for the ecological evaluation of lakes for implementation of the EU water framework directive: makrophytes and phytobenthos (Schaumburg et al., 2007). The main criterion for a selection was dominance by Elodea nuttalli or Najas intermedia. At each location a 30 $\mathrm{m}$ wide and 25 or $50 \mathrm{~m}$ long transect (depending on the extent of the macrophyte vegetation) was determined. 
For the experiment rolls with either $2.1 \times 25$ or $2.1 \times 50$ $\mathrm{m}$ untreated jute textile (mesh size $0.5 \mathrm{~mm}, 300 \mathrm{gm}^{-2}$ ) were used. Iron rods with a length of $3 \mathrm{~m}$ were attached to each narrow side of the textiles as a grip to simplify the handling of the rolls, but they were removed after the mattings were fixed at their final positions. The jute mattings were placed in bankside water at a depth of $1 \mathrm{~m}$ by scientific divers. The mattings were then anchored to the sediment with iron hooks and were unreeled towards the centre of the lake. Three strips of jute matting were placed within the transect to cover a total area of 150 or $300 \mathrm{~m}^{2}$, respectively (Tab. 2). The mattings were laid with an overlap to ensure a close covering and if necessary stones from the bottom of the lakes were used as additional weight. The experimental sites were treated with jute matting in
April 2011 and were visited by divers every two weeks until November 2011. During the visits the divers recorded various measurements concerning the condition of the jute textile. These included: i) the condition of the jute weave, more specifically the damages caused by fishermen, divers, swimmers, etc. ( $1=$ intact, $2=$ reduced tensile strength, but intact, $3=$ damaged); ii) the level of natural disintegration of the weaving by microbial decomposition $(0=$ no sign of degradation, $1=$ disintegrates on contact, $2=$ partially degraded, $3=$ completely degraded); iii) the extent of sedimentation on jute matting $(0=$ no sign of sedimentation, $1=$ partially covered/jute still visible, $2=$ completely covered); iv) the visible amount of gas evolution and accumulation beneath the matting ( $-=$ almost none: no visible gas bubbles/no buckling in the matting,
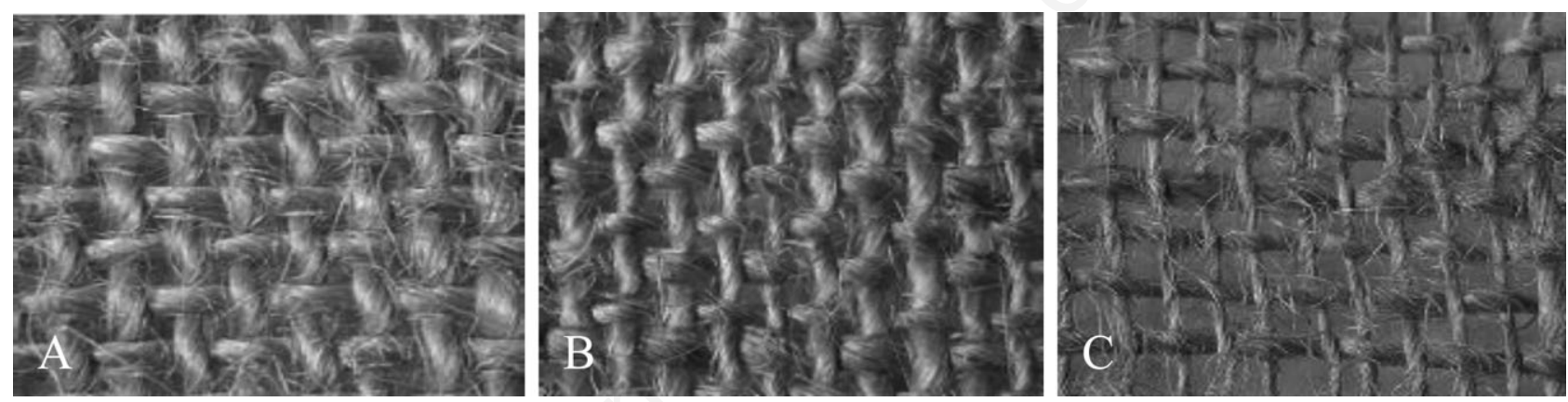

Fig. 1. Jute textiles used during the laboratory experiments. A) mesh size $0.5 \mathrm{~mm}, 300 \mathrm{gm}^{-2}$; B) mesh size $1 \mathrm{~mm}, 200 \mathrm{gm}{ }^{-2}$; C) mesh size $2 \mathrm{~mm}, 150 \mathrm{gm}^{-2}$.

Tab. 1. Physical parameters above and below the jute cover at the end of the preliminary experiment.

\begin{tabular}{|c|c|c|c|c|c|c|c|c|}
\hline \multirow[t]{2}{*}{ Textile } & \multicolumn{2}{|c|}{ Mean pH } & \multicolumn{2}{|c|}{ Mean conductivity $(\mu \mathrm{S})$} & \multicolumn{2}{|c|}{ Mean $\mathrm{O}_{2}(\%)$} & \multicolumn{2}{|c|}{ Mean $\mathrm{O}_{2}(\mathrm{mg} / \mathrm{L})$} \\
\hline & $\mathrm{a}$ & $\mathrm{b}$ & $\mathrm{a}$ & $\mathrm{b}$ & a & $\mathrm{b}$ & $\mathrm{a}$ & $\mathrm{b}$ \\
\hline $0.5 \mathrm{~mm} / 300 \mathrm{gm}^{-2}$ & 8.5 & 8.5 & $417( \pm 10)$ & $399( \pm 12)$ & $73.3( \pm 2.8)$ & $70.4( \pm 2.3)$ & $7.1( \pm 0.2)$ & $7.0( \pm 0.4)$ \\
\hline $1 \mathrm{~mm} / 200 \mathrm{gm}^{-2}$ & 8.5 & 8.5 & $422( \pm 19)$ & $408( \pm 13)$ & $74.3( \pm 2.8)$ & $73.0( \pm 2.3)$ & $7.1( \pm 0.4)$ & $7.1( \pm 0.4)$ \\
\hline $2 \mathrm{~mm} / 150 \mathrm{gm}^{-2}$ & 8.5 & 8.5 & $414( \pm 15)$ & $410( \pm 10)$ & $77.3( \pm 3.2)$ & $73.3( \pm 3.4)$ & $7.3( \pm 0.6)$ & $6.9( \pm 0.5)$ \\
\hline Control & 8.5 & - & $422( \pm 10)$ & - & $75.4( \pm 6.3)$ & - & $7.2( \pm 0.6)$ & - \\
\hline
\end{tabular}

$a$, above jute cover; $b$, below jute cover. Values within brackets indicate \pm standard deviation.

Tab. 2. Experimental sites where jute matting was deployed to control the invasive species.

\begin{tabular}{|c|c|c|c|c|c|c|c|c|c|}
\hline Lake & $\begin{array}{l}\text { Size } \\
\left(\mathrm{km}^{2}\right)\end{array}$ & $\begin{array}{l}\text { Maximum } \\
\text { depth } \\
(\mathrm{m})\end{array}$ & $\begin{array}{l}\text { Trophic } \\
\text { level }\end{array}$ & $\begin{array}{c}\text { Mean } \\
\text { temperature } \\
\left({ }^{\circ} \mathrm{C}\right)\end{array}$ & $\begin{array}{c}\text { Covered } \\
\text { area } \\
\left(\mathrm{m}^{2}\right)\end{array}$ & $\begin{array}{l}\text { Depth } \\
\text { mattings } \\
(\mathrm{m})\end{array}$ & $\begin{array}{l}\text { Latitude } \\
(\mathrm{N})\end{array}$ & $\begin{array}{l}\text { Longitude } \\
\text { (E) }\end{array}$ & Usage \\
\hline Freigericht & 0.26 & 5 & Mesotrophic & 25 & 300 & $1.0-3.0$ & $50^{\circ} 05^{\prime} 07^{\prime \prime}$ & $9^{\circ} 00^{\prime} 21^{\prime \prime}$ & $\begin{array}{l}\text { Fishing, sailing, } \\
\text { camping, bathing }\end{array}$ \\
\hline Waging & 6.61 & 27 & Mesotrophic & 21 & 150 & $1.0-4.5$ & $47^{\circ} 55^{\prime} 43^{\prime \prime}$ & $12^{\circ} 48^{\prime} 13^{\prime \prime}$ & \\
\hline Ringsee & 0.14 & 5 & Mesotrophic & 18 & 150 & $1.0-3.3$ & $47^{\circ} 41^{\prime} 45^{\prime \prime}$ & $11^{\circ} 44^{\prime} 14^{\prime \prime}$ & \\
\hline Karpfsee & 0.11 & 3 & Eutrophic & 25 & 150 & $1.0-2.0$ & $47^{\circ} 39^{\prime} 52^{\prime \prime}$ & $11^{\circ} 18^{\prime} 30^{\prime \prime}$ & $\begin{array}{l}\text { Formerly fish } \\
\text { farming (in restoration) }\end{array}$ \\
\hline
\end{tabular}

N, North; E, East. 
$\mathrm{o}=$ some: low emissions of gas/little buckling in the matting, $+=$ high: frequent gas emissions/increased buckling, $++=$ very high: large and frequent gas emissions/affected areas are floating); and $\mathrm{v}$ ) visible changes in the sediment colour beneath the matting $(0=$ no visible changes, $1=$ slight change in colour, $2=$ considerable change in colour).

In June/July 2011, at the end of the main growth period in August/September 2011, and in June/July 2012 an assessment of the macrophytes was performed at each location. Macrophytes within the $30 \mathrm{~m}$ wide and $25(50) \mathrm{m}$ long control transect were documented for the assessment and classified into five groups based on their occurrence ( $1=$ very rare; $2=$ rare; $3=$ common; $4=$ frequent; $5=$ abundant, predominant) (Kohler, 1978; Melzer, 1999). Additionally, in August/September 2011 and in June/July 2012 three randomly placed $1 \mathrm{~m}^{2}$ quadrats were used to determine the vegetation cover in 5\% steps. Simultaneously, the same method was used to assess the macrophytes within the treated areas.

\section{Statistical analysis}

Statistical analysis was conducted using the free statistics software R (version 2.10.1). Data from the measurements were analysed with ANalysis Of VAriance (ANOVA). Data were tested for homogeneity, normality and linearity to meet the assumptions of the statistical analysis, and transformed, if necessary. Significant differences were at the 0.05 probability level unless stated otherwise.

\section{RESULTS}

\section{Preliminary experiment}

Several Elodea nuttallii covered with the $150 \mathrm{gm}^{-2}$ (mesh size $2 \mathrm{~mm}$ ) and the $200 \mathrm{gm}^{-2}$ (mesh size $1 \mathrm{~mm}$ ) textiles were able to penetrate the material and showed a significant increase in sprout length and biomass compared to the plants covered with the heavy textile (Tab. 3). The plants shaded with the $300 \mathrm{gm}^{-2}$ (mesh size $0.5 \mathrm{~mm}$ ) textile, on the other hand, did not penetrate the weaving, were significantly smaller and lighter, and showed first signs of degradation (Tab. 3). The water above and below the cover showed no significant differences when comparing the physical parameters $\mathrm{pH}$ level, $\mathrm{O}_{2}$ concentration and conductivity, indicating that the exchange of gas and nutrients was undisturbed. Based on these results field trials with the $300 \mathrm{gm}^{-2}$ textiles were launched in spring 2011.

\section{Field trail}

The jute matting proved to be very effective in controlling the growth of Najas intermedia in the lakes of this study. None of the treated sites showed signs of Najas plants until the end of the vegetation period in September, while the uncovered control transects were dominated by Najas intermedia (Tabs. 4 and 5). The matting, on the other hand, was less effective in inhibiting the growth of Elodea nuttallii. While Elodea plants beneath the matting could not penetrate the textile, sprouts and fragments having drifted onto the cover as well as branches from nearby plants were able to root through the textile (Tabs. 4 and 5). Therefore, Elodea was able to gain a foothold in the treated areas, but was not able to reach the same extent as the untreated populations. Overall, the spread of Elodea nuttallii was reduced by 50 to $75 \%$ in the treated areas compared to the control transects.

A number of indigenous non-invasive plants were recorded growing through the weave of the jute matting (Tabs. 4 and 5). These included Myriophyllum spicatum L., Potamogeton frisii L., Potamogeton pusillus L., and various Charales (mainly Chara aspera C.L.Willdenow), which were most successful in colonising the now Elodeaand Najas-free area. The frequencies as well as the vegetation cover of Potamogeton pussilus and the Charales increased in the treated areas. This effect was only noted at locations where other macrophytes (apart from Elodea nuttallii and Najas intermedia) were present in the control transects (lakes Ringsee, Karpfsee and Freigericht-Ost). The treated area at lake Waging remained free of macrophytes until the end of the vegetation period.

The mattings themselves remained almost unchanged at lakes Waging, Ringsee and Freigericht-Ost (Tab. 6). After six months under water, the jute textiles showed no signs of degradation or visible damages. One month after the mattings had been placed they were at least partially covered with sediment and remained covered during the

Tab. 3. Sprout length and longitudinal growth rate at the end of the preliminary experiment.

\begin{tabular}{lcccc}
\hline Textile & Mean sprout length $(\mathrm{cm})$ & Mean LGR $\left(\mathrm{cm} \mathrm{d}^{-1}\right)$ & Mean dry weight $(\mathrm{mg})$ & Biomass per cm $\left.(\mathrm{mg} \mathrm{cm})^{-1}\right)$ \\
\hline $0.5 \mathrm{~mm} / 300 \mathrm{gm}^{-2}$ & $6.7( \pm 0.4)^{\mathrm{a}}$ & $0.03( \pm 0.01)^{\mathrm{a}}$ & $7( \pm 4)^{\mathrm{a}}$ & $1( \pm 1)^{\mathrm{a}}$ \\
$1 \mathrm{~mm} / 200 \mathrm{gm}^{-2}$ & $8.5( \pm 2.2)^{\mathrm{b}}$ & $0.06( \pm 0.04)^{\mathrm{b}}$ & $59( \pm 42)^{\mathrm{b}}$ & $7( \pm 3)^{\mathrm{b}}$ \\
$2 \mathrm{~mm} / 150 \mathrm{gm}^{-2}$ & $17.6( \pm 8.2)^{\mathrm{c}}$ & $0.21( \pm 0.14)^{\mathrm{c}}$ & $115( \pm 75)^{\mathrm{c}}$ & $6( \pm 2)^{\mathrm{b}}$ \\
Control & $18.4( \pm 9.8)^{\mathrm{c}}$ & $0.22( \pm 0.16)^{\mathrm{c}}$ & $128( \pm 91)^{\mathrm{c}}$ & $7( \pm 2)^{\mathrm{b}}$ \\
\hline
\end{tabular}

LGR, longitudinal growth rate. Values within brackets indicate \pm standard deviation. Different letters in the same column indicate significant differences $(P<0.05)$. 
whole experiment. Only minor gas evolution and gas accumulation was recorded at the three locations and this had no apparent impact (e.g. drifting), on the position of the cover or its effectiveness. At lake Karpfsee, on the other hand, the jute textiles were partially covered with algae within two weeks and completely covered after one month, which clogged the jute weave and prevented the exchange of gas, affecting the colour of the sediment below the cover (Tab. 6). Because of the strong gas evolution underneath the cover and the increased gas accumulation, numerous folds appeared along the matting. Between those folds sediment was able to accumulate and allowed fragments of Elodea nuttallii to establish new populations on the treated area. As a secondary effect, the folds reduced the expanse of the jute cover and therefore its effectiveness by $1 / 3$. The exposed areas were quickly repopulated by the surrounding macrophytes, mainly Elodea nuttallii, and were indistinguishable from the untreated areas by the end of the vegetation period (Tabs. 4 and 5). Although the effect of the jute matting on Elodea nuttallii was limited at lake Karpfsee, the matting was able to reduce the growth of Elodea nuttallii: Elodea nuttallii reached only a frequency of 3 and a cover of $40 \%$ $( \pm 0)$ in the covered area, in contrast to a frequency of $5 \%$ and a cover of $80 \%( \pm 10)$ in the control transect.

In 2012, 15 months after the treatment, the situation at lakes Freigericht-Ost and Karpfsee changed significantly. The jute mattings at both locations were partially degraded and severely damaged (Tab. 6), which enabled Elodea nuttalli to repopulate large parts of the treated areas. At lake Karpfsee, for example, Elodea nuttalli was able to cover $70 \%$ of the treated area (Tab. 5). The jute

Tab. 4. Frequency of macrophytes in the experimental transects.

\begin{tabular}{|c|c|c|c|c|c|c|c|}
\hline \multirow[t]{2}{*}{ Lake } & Month & Elodea nuttallii & Elodea canadensis & Najas intermedia & Potamogeton pusillus & Myriophyllum spicatum & Charales \\
\hline & & \multicolumn{6}{|c|}{ Control transect } \\
\hline \multirow[t]{4}{*}{ Freigericht } & 0.5 & 1 & - & - & - & 1 & - \\
\hline & 3 & 2 & - & 4 & - & 2 & 1 \\
\hline & 6 & 3 & - & 5 & 2 & 2 & 2 \\
\hline & 15 & 3 & - & 3 & 1 & 2 & 3 \\
\hline \multirow[t]{4}{*}{ Waging } & 0.5 & - & - & - & - & - & - \\
\hline & 3 & - & - & 4 & - & - & - \\
\hline & 6 & - & - & 5 & - & - & - \\
\hline & 15 & - & - & 5 & - & - & - \\
\hline \multirow{4}{*}{ Ringsee } & 0.5 & 2 & 1 & - & - & - & - \\
\hline & 3 & 3 & 3 & - & - & 1 & - \\
\hline & 6 & 4 & 3 & - & - & 1 & 1 \\
\hline & 15 & 3 & 2 & - & - & 1 & - \\
\hline \multirow[t]{5}{*}{ Karpfsee } & 0.5 & 2 & - & - & - & 1 & - \\
\hline & 3 & 4 & - & - & - & 1 & - \\
\hline & 6 & 5 & - & - & - & 2 & - \\
\hline & 15 & 4 & - & - & - & 2 & - \\
\hline & & \multicolumn{6}{|c|}{ Covered transect } \\
\hline \multirow[t]{4}{*}{ Freigericht } & 0.5 & - & - & - & - & - & - \\
\hline & 3 & $1(\mathrm{o})$ & - & - & $2(\mathrm{t})$ & $1(\mathrm{t})$ & $1(\mathrm{t})$ \\
\hline & 6 & $1(\mathrm{o})$ & - & - & $3(\mathrm{t})$ & $3(\mathrm{t})$ & $3(\mathrm{t})$ \\
\hline & 15 & $3(0)$ & - & $1(0)$ & $2(t)$ & $2(\mathrm{t})$ & $3(t)$ \\
\hline \multirow[t]{4}{*}{ Waging } & 0.5 & - & - & - & - & - & - \\
\hline & 3 & - & - & $1(\mathrm{o})$ & - & - & - \\
\hline & 6 & - & - & - & - & - & - \\
\hline & 15 & - & - & $1(\mathrm{o})$ & - & - & - \\
\hline \multirow[t]{4}{*}{ Ringsee } & 0.5 & - & - & - & - & - & - \\
\hline & 3 & $1(\mathrm{o})$ & - & - & - & - & $1(t)$ \\
\hline & 6 & $2(\mathrm{o})$ & $1(\mathrm{o})$ & - & - & - & $1(t)$ \\
\hline & 15 & $2(0)$ & $3(0)$ & - & - & - & $1(\mathrm{t})$ \\
\hline \multirow[t]{4}{*}{ Karpfsee } & 0.5 & - & - & - & - & - & - \\
\hline & 3 & $4(0)$ & - & - & - & - & - \\
\hline & 6 & $3(0)$ & - & - & - & - & - \\
\hline & 15 & $4(0)$ & - & - & - & - & - \\
\hline
\end{tabular}

1, very rare; 2, rare; 3, common; 4, frequent; 5, abundant, predominant (Kohler, 1978); o, plants growing on the jute matting; t, plants growing through the jute matting. 
Tab. 5. Percentage vegetation cover in the experimental transects. Three randomly placed $1.0 \mathrm{~m}^{2}$ quadrats were examined at each site.

\begin{tabular}{|c|c|c|c|c|c|c|c|}
\hline \multirow[t]{2}{*}{ Lake } & Month & Elodea nuttallii & Elodea canadensis & Najas intermedia & Potamogeton pussilus & Myriophyllum spicatum & Charales \\
\hline & & \multicolumn{6}{|c|}{ Control transect } \\
\hline \multirow[t]{2}{*}{ Freigericht } & 6 & $15( \pm 5)$ & - & $60( \pm 10)$ & $5( \pm 0)$ & $5( \pm 0)$ & $5( \pm 0)$ \\
\hline & 15 & $40( \pm 5)$ & - & $10( \pm 5)$ & $<5$ & $5( \pm 0)$ & $15( \pm 10)$ \\
\hline \multirow[t]{2}{*}{ Waging } & 6 & - & - & $95( \pm 0)$ & - & - & - \\
\hline & 15 & - & - & $30( \pm 0)$ & - & - & - \\
\hline \multirow[t]{2}{*}{ Ringsee } & 6 & $40( \pm 20)$ & $30( \pm 15)$ & - & - & $<5$ & $<5$ \\
\hline & 15 & $20( \pm 5)$ & $10( \pm 0)$ & - & - & $<5$ & - \\
\hline \multirow[t]{3}{*}{ Karpfsee } & 6 & $80( \pm 10)$ & - & - & - & $5( \pm 5)$ & - \\
\hline & 15 & $80( \pm 5)$ & - & - & - & $5( \pm 0)$ & - \\
\hline & & \multicolumn{6}{|c|}{ Covered transect } \\
\hline \multirow[t]{2}{*}{ Freigericht } & 6 & $<5$ & - & - & $20( \pm 0)$ & $20( \pm 0)$ & $20( \pm 5)$ \\
\hline & 15 & $35( \pm 10)$ & - & $<5$ & $5( \pm 0)$ & $5( \pm 0)$ & $20( \pm 5)$ \\
\hline \multirow[t]{2}{*}{ Waging } & 6 & - & - & - & - & - & - \\
\hline & 15 & - & - & $5( \pm 5)$ & - & - & - \\
\hline \multirow[t]{2}{*}{ Ringsee } & 6 & $10( \pm 10)$ & $5( \pm 5)$ & - & - & - & $<5$ \\
\hline & 15 & $10( \pm 0)$ & $15( \pm 5)$ & - & - & - & $<5$ \\
\hline \multirow[t]{2}{*}{ Karpfsee } & 6 & $40( \pm 0)$ & - & - & - & - & - \\
\hline & 15 & $70( \pm 5)$ & - & - & - & - & - \\
\hline
\end{tabular}

Values within brackets indicate \pm standard deviation ( $5 \%$ steps).

Tab. 6. Jute matting parameters monitored during the experiment.

\begin{tabular}{|c|c|c|c|c|c|c|c|}
\hline Lake & $\begin{array}{l}\text { Trial period } \\
\text { (months) }\end{array}$ & $\begin{array}{l}\text { Condition } \\
\text { of jute }\end{array}$ & Degradation $^{\mathrm{ii}}$ & Sedimentation $^{\mathrm{iii}}$ & Gas evolution $^{\text {iv }}$ & Gas accumulation $^{\text {iv }}$ & Sediment below matting ${ }^{\mathrm{v}}$ \\
\hline \multirow[t]{5}{*}{ Freigericht } & 0.5 & 1 & 0 & 0 & - & - & 0 \\
\hline & 1 & 1 & 0 & 0 & - & - & 0 \\
\hline & 3 & 1 & 0 & 1 & - & - & 0 \\
\hline & 6 & 2 & 0 & 1 & - & - & 0 \\
\hline & 15 & 3 & 2 & 2 & - & - & 0 \\
\hline \multirow[t]{5}{*}{ Waging } & 0.5 & 1 & 0 & 0 & - & - & 0 \\
\hline & 1 & 1 & 0 & 0 & - & - & 0 \\
\hline & 3 & 1 & 0 & 1 & - & - & 0 \\
\hline & 6 & 1 & 0 & 1 & - & - & 0 \\
\hline & 15 & 2 & 1 & 1 & - & - & 0 \\
\hline \multirow[t]{5}{*}{ Ringsee } & 0.5 & 1 & 0 & 1 & - & - & 0 \\
\hline & 1 & 1 & 0 & 2 & - & - & 0 \\
\hline & 3 & 1 & 0 & 2 & - & - & 0 \\
\hline & 6 & 1 & 0 & 2 & o & o & 0 \\
\hline & 15 & 2 & 1 & 2 & - & - & 0 \\
\hline \multirow[t]{5}{*}{ Karpfsee } & 0.5 & 1 & 0 & 1 & o & o & 0 \\
\hline & 1 & 1 & 0 & 2 & + & + & 0 \\
\hline & 3 & 1 & 0 & 2 & ++ & ++ & 0 \\
\hline & 6 & 2 & 0 & 2 & ++ & ++ & 1 \\
\hline & 15 & 3 & 2 & 2 & o & o & 1 \\
\hline
\end{tabular}

${ }^{i} 1$, intact; 2 , reduced tensile strength, but intact; 3 , damaged. ${ }^{i i} 0$, no sign of degradation; 1 , disintegrates on contact; 2 , partially degraded. ${ }^{i i} 0$, no sign of sedimentation; 1 , jute still visible; 2, completely covered. ${ }^{{ }^{i v}}$, almost none; o, some; +, high; ++, very high. ${ }^{v} 0$, no visible changes; 1 , slight change in colour. 
fabric at lake Ringsee, on the other hand, was still intact, but the tensile strength of the weaving was considerably reduced. The intact matting still affected the growth of Elodea nuttallii after 15 months, therefore the frequency and vegetation cover of Elodea nuttallii remained almost the same compared to the situation after 6 months.

Najas intermedia plants at the treated areas in lakes Waging and Freigericht-Ost showed only marginal growth 15 months after the treatment (Tabs. 4 and 5), although the jute matting at lake Freigericht-Ost was partially degraded and damaged. As a result, Najas intermedia was only able to repopulate less than $10 \%$ of the treated areas and the non-invasive species (e.g. Charales) showed a slight increase in frequency and vegetation cover.

\section{DISCUSSION}

Managing invasive macrophytes is often a complex, expensive and time consuming task. Although various management strategies have been developed, the number of available control methods is often limited by legal restrictions and narrow budgets (Pieterse and Murphy, 1990). The method commonly used to control unwanted and invasive weeds is cutting and harvesting. This method, however, has a number of advantages which favour its implementation, for example the removal of nutrients and biomass from the water (Hilt et al., 2006; Pieterse and Murphy, 1990). One of the major drawbacks of harvesting is the possibility of unintentionally spreading the weeds through fragments or seed. The plants have to be cut down close to the sediment to effectively control the growth; therefore, the unwanted invasive plants as well as the non-invasive plants are affected. Jute mattings might be the solution to these problems, especially if used against specific plants like Elodea nuttallii and Najas intermedia or to treat specific locations like bathing areas. The biodegradable jute matting used in this experiment has some advantages over cutting and harvesting. The handling of jute matting is simple and does not require special equipment or training, because the jute mattings can be placed by divers or by boat (Caffrey et al., 2010). The material has no buoyancy and sinks quickly to the bottom of the lake, therefore the matting can be placed very accurately (Caffrey et al., 2010) and if necessary, the position of the matting can be corrected by divers during or after the placing. Because of this, jute matting might also be useful as a prevention tool to suppress small patches of invasive plants, preventing their spread within the lake at an early stage of colonisation. The use of jute matting does not contribute to an additional spread of the invasive macrophytes, because the plants (plants fragments) are completely covered by the matting. Additionally, the development of macrophytes with a seed-based reproduction (e.g. Najas intermedia) is inhibited when the matting is placed before germination. Therefore, neither fragments nor seeds can disperse.
The main advantage of jute is its ability to suppress a particular unwanted weed on the one hand and on the other hand to allow native, non-invasive weeds like Charales or Potamogeton pusillus to grow through the weave. The positive effect of this on the macrophyte population was visible at location lake Freigericht-Ost. The untreated areas were dominated by Najas intermedia and Elodea nuttallii and contained only a few plants of other species. The area covered with jute showed no signs of Najas intermedia and only a marginal number of Elodea nuttallii or Elodea canadensis plants, but an increased population of Potamogeton pusillus and Charales. However, this effect only occurs if these macrophyte species are already present at a site prior to treatment. At location lake Waging, for example, the treated area remained vegetationfree because Najas intermedia was the only existing species. It might be possible to induce a follow-up population or promote the growth of specific species by applying oospores or seeds of wanted macrophytes to the jute weave, but this method is so far untested and further research and field trials are needed to determine its effectiveness and feasibility.

The success of the management attempt varied depending on the target species. The jute matting treatments were very successful in suppressing Najas intermedia during the vegetation period in 2011 and had a noticeable effect on the population of Najas intermedia in 2012. The reason for this success was that neither the shoots nor the roots of Najas intermedia were able to penetrate the jute weaving, which reduced the amount of plants and therefore the amount of produced seeds in the treated areas. As a result, fewer Najas intermedia plants appeared during the following vegetation period, although the jute matting treatments had lost most of their effect.

The long term effect of the mattings on the growth and spread of Elodea nuttallii on the other hand, was limited and closely related to the condition of the jute mattings. As long as the mattings were still intact, the growth and spread of Elodea nuttallii were significantly reduced. However, after one year, when the mattings were degraded and damaged, the plant abundances recorded in the treated areas were comparable to the control transect results. In contrast to this, the immediate effect was reduced by the growth strategy of Elodea nuttalli, more precisely its ability of to root through the jute matting and its ability to regenerate from small fragments (Barrat-Segretain et al., 2002). This allowed Elodea plants to partially recolonise the treated areas and apparently reduced the management efficiency of the jute matting, but, the cover was still successful in controlling the pre-existing Elodea plants at all locations. At location lake Karpfsee, the immediate effect was additionally reduced by the special environmental conditions. Lake Karpfsee was formerly used for fish farming; because of this the water and presumably the sediment contained 
large amount of nutrients and organic matter, which stimulated the growth of algae, and the production of gas in the sediment (Schwoerbel and Brendelberger, 2005). The combination of very high gas evolution and the clogged jute weaving allowed Elodea nuttallii to regain a foothold in the treated areas during the first vegetation period. The solution to increase the long term and immediate effect of the jute matting on Elodea nuttalli could be the use of a thicker and more resilient weaving with a smaller mash size. This would reduce the speed of the degradation and inhibit Elodea plants from rooting through the matting, but might have a negative effect on the non-invasive macrophytes and the gas accumulation. The integration of small areas with lager mesh sizes, on the other hand, could reduce the gas accumulation and therefore the problems caused by smaller mesh sizes and high gas evolution from the sediment, but additional testing is necessary to prove those ideas.

\section{CONCLUSIONS}

Results from this study and the experiments conducted by Caffrey et al. (2010) in Ireland have proved that jute matting is effective against invasive species like Najas intermedia, Elodea nuttallii and Lagarosiphon major (Ridl.) Moss (Caffrey et al., 2010) for at least one vegetation period, and that the jute matting can be adapted to the respective needs to control unwanted weeds. Still, the results also show that certain circumstances can reduce the effectiveness and that the long term effect of the treatment depends on the condition of the material, precisely its resilience.

Further testing and field trials with various mesh sizes, more resistant fabrics and under different environmental conditions as well as with different invasive species should solve most of the problems which appeared during the present study and might prove that jute cover is a valuable method for the control of invasive macrophytes and for lake restoration.

\section{ACKNOWLEDGMENTS}

The study is part of the Bavarian Research Cooperation FORKAST: impact of climate on aquatic ecosystems and climatic adaption strategies, funded by the Bavarian State Ministry of Science, Research and the Arts, and the Bavarian State Ministry of the Environment and Public Health. Our special thanks to all scientific divers, students and colleagues of the Limnologische Station Iffeldorf.

\section{REFERENCES}

Agami M, Waisel Y, 1984. Germination of Najas marina L. Aquat. Bot. 19:37-44.

Barrat-Segretain MH, 2005. Competition between invasive and indigenous species: impact of spatial pattern and developmental stage. Plant. Ecol. 180:153-60.
Barrat-Segretain MH, Elger A, Sagnes P, Puijalon S, 2002. Comparison of three life-history traits of invasive Elodea canadensis Michx. and Elodea nuttallii (Planch.) H. St. John. Aquat. Bot. 74:299-313.

Bolle C, 1865. [Eine Wasserpflanze mehr in der Mark]. [Article in German]. Verh. Bot. Ver. Prov. Brandenburg 7:1-15.

Boylen CW, Eichler LW, Sutherland JW, 1996. Physical control of Eurasian watermilfoil in an oligotrophic lake. Hydrobiologia 340:213-8.

Caffrey JM, Acevedo S, 2007. Status and management of Lagarosiphon major in Lough Corrib 2007. Central Fisheries Board, Dublin: 98 pp.

Caffrey JM, Millane M, Evers S, Moran H, Butler M, 2010. A novel approach to aquatic weed control and habitat restoration using biodegradable jute matting. Aquatic Invasions 5:123-9.

Erhard D, Gross EM, 2006. Allelopathic activity of Elodea canadensis and Elodea nuttallii against epiphytes and phytoplankton. Aquat. Bot. 85:203-11.

Erhard D, Pohnert G, Gross EM. 2007. Chemical defense in Elodea nuttallii reduces feeding and growth of aquatic herbivorous Lepidoptera. J. Chem. Ecol. 33:1646-61.

George G, 2010. The impact of climate change on European lakes. Springer Verlag, Heidelberg: 507 pp.

Gunnison D, Barko JW. 1992. Factors influencing gas evolution beneath a benthic barrier. J. Aquat. Plant Manage. 30:23-8.

Handley R, Davy A. 2005. Temperature effects on seed maturity and dormancy cycles in an aquatic annual, Najas marina, at the edge of its range. J. Ecol. 93:1185-93.

Hilt S, Gross EM, Hupfer M, Morscheid H, Mählmann J, Melzer A, Poltz J, Sandrock S, Scharf E-M, Schneider S, van de Weyer K, 2006. Restoration of submerged vegetation in shallow eutrophic lakes: a guideline and state of the art in Germany. Limnologica 36:155-71.

Hussner A, Van De Weyer K, Gross EM, Hilt S, 2010. Comments on increasing number and abundance of non-indigenous aquatic macrophyte species in Germany. Weed Res. 50:519-26.

IPCC, 2007. Synthesis report. Intergovernmental Panel on Climate Change, Geneva: $56 \mathrm{pp}$.

Kelly DJ, Hawes I, 2005. Effects of invasive macrophytes on littoral-zone productivity and foodweb dynamics in a New Zealand high-country lake. J. N. Am. Benthol. Soc. 25:30020.

Kohler A, 1978. [Methoden der Kartierung von Flora und Vegetation von Süßwasserbiotopen]. [Article in German]. Landschaft und Stadt 10:73-85.

Mayer RJ, 1978. Aquatic weed management by benthic semi barriers. J. Aquat. Plant Manage. 16:31-3.

Melzer A, 1999. Aquatic macrophytes as tools for lake management. Hydrobiologia 396:181-90.

Pieterse AH, Murphy KJ, 1990. Aquatic weeds: the ecology and management of nuisance aquatic vegetation. Oxford University Press, Oxford: 616 pp.

Podraza P, Brinkmann T, Evers P, von Felde D, Forst U, Klopp R, Knotte H, Kühlmann M, Kuk M, Lipka P, Nusch EA, Stengert M, Wessel M, van de Weyer K, 2008. [Untersuchungen zur Massenentwicklung von Wasserpflanzen in den Ruhrstauseen und Gegenmaßnahmen. F \& E- Vorhaben im Auftrag des Ministeriums für Umwelt und Naturschutz, 
Landwirtschaft und Verbraucherschutz des Landes RW]. [Report in German]. Available from: http://www.ruhrverband.de/fileadmin/pdf/elodea_abschlussbericht.pdf

Schaumburg J, Schranz C, Stelzer D, Hofmann G, 2007. Instructions for the ecological evaluation of lakes for implementation of the EU water framework directive: makrophytes and phytobenthos. Bavarian Environment Agency ed., Augsburg: 69 pp. Available from: http://www.lfu.bayern.de/ wasser/gewaesserqualitaet_seen/phylib_englisch/instruction_protocols/doc/instruction_protocol_lakes.pdf

Schwoerbel J, Brendelberger H, 2005. [Einführung in die Limnologie]. [Book in German]. Elsevier, Amsterdam: 340 pp.
Ussery TA, Eakin HL, Payne BS, Miller AC, Barko JW, 1997. Effects of benthic barriers on aquatic habitat conditions and macroinvertebrate communities. J. Aquatic Plant Manage. 35:69-73.

Weber-Oldecop DW, 1977. [Elodea nuttallii (Planch.) St. John (Hydrocharitaceae), eine neue limnische Phanerogame der deutschen Flora]. [Article in German]. Arch. Hydrobiol. 79:397-403.

Yang CZ, Yaniger SI, Jordan CV, Klein DJ, Bittner GD, 2011. Most plastic products release estrogenic chemicals: a potential health problem that can be solved. Environ. Health Perspect. 119:989-96. 